\title{
mssaico
}

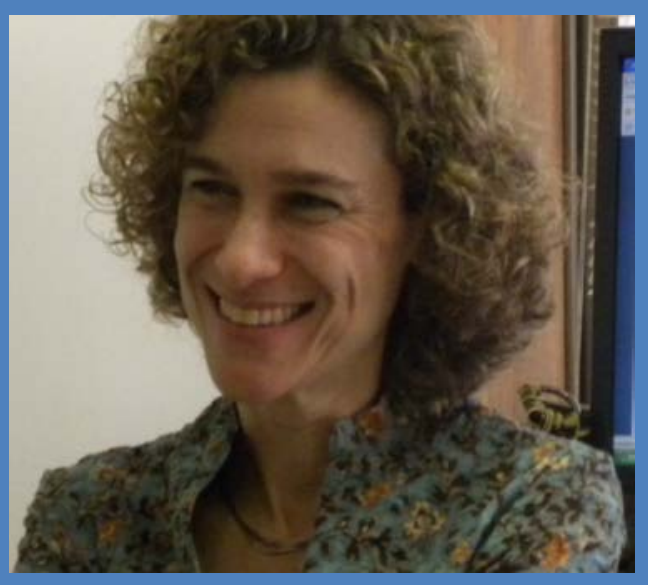

\section{Entrevista de}

Luciana Quillet

Heymann

Concedida a

Helen Nunes';

Isabela Cruz ${ }^{2}$

${ }^{1}$ Doutoranda pelo Programa de

Pós-Graduação em História, Política e Bens

Culturais - CPDOC/ FGV.

2 Mestranda do Programa de pós-graduação em

História, Política e Bens Culturais do

CPDOC/FGV.
Luciana Quillet Heymann é doutora em Sociologia pelo Instituto Universitário de Pesquisas do Rio de Janeiro (antigo IUPERJ), mestre em Antropologia Social pelo Museu Nacional e graduada em História pela Universidade Federal do Rio de Janeiro (UFRJ). Integra a equipe do CPDOC desde 1986, sendo hoje professora associada da Escola de Ciências Sociais e do Programa de Pós-graduação em História, Política e Bens Culturais, que coordenou de 06/2012 a 06/2016. É professora colaboradora do Programa de Pós-Graduação em Gestão de Documentos e Arquivos da UNIRIO, vicepresidente da Associação Brasileira de História Oral (2016-2018) eco-editora da revista História Oral. Sua produção acadêmica tem se voltado para o campo da sociologia da memória, tanto no que diz respeito aos processos sociais de construção e institucionalização de acervos pessoais como patrimônio público, quanto no que toca às políticas memoriais e aos usos do passado em contextos de luta por direitos. 


\section{Entrevista com a professora Luciana Quillet Heymann sobre sua obra intitulada: $O$ lugar do arquivo: a construção do legado de Darcy Ribeiro ${ }^{1}$.}

Professora, gostaríamos de conhecer um pouco mais a pesquisa que deu origem a seu livro $O$ lugar do arquivo. Como foi a escolha do objeto de estudo e do referencial teórico? Foram concomitantes, ou a escolha pelo referencial teórico se desenvolveu ao longo da pesquisa?

O meu interesse pelo processo de construção social dos arquivos, de maneira geral, é bastante anterior à minha pesquisa de Doutorado. Eu considero que o marco dessa reflexão é a minha dissertação de Mestrado, defendida no Museu Nacional. Foi uma dissertação na qual eu trabalhei com uma parcela do arquivo Filinto Muller, que é um arquivo depositado no CPDOC. É importante esclarecer que ingressei nessa instituição como estagiária, aos 20 anos de idade e, que ao longo de muitos anos trabalhei exclusivamente no Setor de Documentação, na organização de arquivos pessoais. Então, acho que minha formação profissional foi fundamental para desenvolver um olhar interessado e sensível para os processos envolvidos na transformação de arquivos pessoais em fonte histórica. A escolha por investigar o arquivo de Darcy Ribeiro se deu, certamente, após a experiência de ter coordenado a organização desse arquivo, na Fundação Darcy Ribeiro (Fundar), entre 2000 e 2002, mais ou menos. O arquivo estava depositado em Santa Teresa, numa casa, onde a fundação ainda funciona, embora o arquivo não esteja mais lá fisicamente.

\section{Ele está em Brasília?}

É, ele está em Brasília agora, fechado à consulta. Mas, esse é o fim da história, e gostaria de voltar um pouquinho. A Fundação Darcy Ribeiro contratou o CPDOC para

\footnotetext{
${ }^{1}$ As entrevistadoras agradecem imensamente à professora Luciana Quillet Heymann pela entrevista concedida e, com a mesma, homenageiam o professor Bernardo Buarque de Hollanda que, por meio de sua disciplina História e Teoria Social, as incentivou a conhecer mais sobre a obra da professora.
} 
organizar o arquivo, e eu fiquei responsável pela coordenação desse trabalho. Tive oportunidade de acompanhar e atuar em todas as fases, desde a limpeza da documentação, que estava em centenas de caixas, no sótão dessa casa, até a definição do arranjo e montagem de dossiês. Nós descemos as caixas, higienizamos toda a documentação, sempre de luvas, máscara e jaleco - essa foi, digamos assim, a fase heroica do trabalho! É um arquivo muito grande, muito extenso. Na época, a gente calculou em 50 mil documentos, é muita coisa. Então foram cerca de dois anos, desde a higienização até o começo da descrição das unidades documentais. Eu não ficava lá em tempo integral, mas ia duas vezes por semana, pelo menos. Montamos uma equipe e quando o CPDOC se afastou do trabalho, ao final, a equipe que atuava no projeto foi incorporada à Fundação Darcy Ribeiro e ficou responsável pelo trabalho. Nesse ponto, já distante da rotina da organização do arquivo, eu me dei conta da riqueza de elementos que aquela experiência tinha me trazido. Também é verdade que é bom a gente sair do nosso ambiente profissional. Eu já havia trabalho com um arquivo do CPDOC no meu mestrado e achei interessante refletir sobre outra instituição, com características bastante diferentes. Porque pra mim tinha ficado muito clara uma imbricação forte também, entre o arquivo e a própria Fundação Darcy Ribeiro. Essa é uma dimensão que eu exploro na tese: como a institucionalização do acervo está longe de ser, necessariamente, um processo de delimitação de fronteiras muito claras entre o ambiente privado no qual o arquivo se originou e o ambiente público, institucional. 0 arquivo estava na Fundar, onde foi organizado pelo CPDOC, o que conferiu, vamos dizer, uma dimensão profissional ao trabalho do ponto de vista metodológico etc., mas, no dia a dia, eu percebia uma relação interessante, de uso desse arquivo e, muitas vezes, uma interferência mesmo no arquivo.

\section{É uma dimensão dinâmica?}

Isso. Dimensão que talvez eu tenha explorado menos na minha dissertação de Mestrado e que diz respeito a essa conexão entre o lugar institucional e o arquivo, e não só o lugar do arquivo no sentido de "o lugar do arquivo na construção do legado": também o lugar físico, o espaço, o território no qual o arquivo se situa, e como esse 
estar em determinada instituição produz efeitos.

Com relação ao referencial teórico, sobre o qual você tinha me perguntado também, eu acho que muitos dos autores que utilizei na tese de Doutorado, eu não conhecia no período em que fiz meu Mestrado. Na verdade, foi interessante perceber como meus interesses no Mestrado se conectavam a uma literatura que eu desconhecia na época, e que eu fui conhecer na fase do Doutorado, quando foi importante, para mim, fazer uma discussão sobre o campo dos arquivos e sobre teoria arquivística. De alguma maneira, discutir princípios da teoria arquivística e sua aplicação - e limites - para trabalhar com arquivos pessoais, discussão que faço no primeiro capítulo do livro. Isso é uma coisa que eu não tinha feito no meu Mestrado. Então eu acho que essa literatura, os chamados pós-modernos na Arquivologia, eu fui buscar no momento em que eu já estava no Doutorado e querendo fazer essa discussão.

Quer dizer, a hipótese já existia a partir da sua experiência, e depois a pesquisa de Doutorado confirmou a hipótese.

Isso. O problema, sobretudo, era um problema que eu já trazia desde muito tempo. Quais são os processos que definem a configuração das fontes documentais preservadas em instituições de guarda, sobretudo, no caso dos arquivos pessoais? No Doutorado, eu acho que eu vou um pouco além, pensando não só na configuração da fonte - no processo de acumulação documental por parte do titular, depois no processo de doação dos documentos a uma instituição e no processo de organização do arquivo -, mas eu discuto também a dimensão institucional, algo que eu não tinha avançado no Mestrado, que é essa imbricação entre arquivo e instituição, no caso, a Fundação Darcy Ribeiro.

E, assim, durante a organização do arquivo do Darcy, houve algum momento de tensão com os gestores da Fundação? Como se lida com isso, geralmente?

A minha convivência na Fundação Darcy Ribeiro, durante dois anos ou um 
pouco mais, me possibilitou perceber a relação afetiva e, ao mesmo tempo, as expectativas que eram depositadas no arquivo. Em primeiro lugar, evidentemente, o arquivo era visto como um patrimônio da Fundação Darcy Ribeiro. Eles logo perceberam, pelo interesse dos pesquisadores em consultar os documentos, que aquele era um acervo valioso para a pesquisa histórica. A primeira fase de organização do arquivo, coordenada pelo CPDOC, foi financiada pela FAPERJ; a segunda fase foi financiada pela Fundação CESGRANRIO... ou seja, os gestores da Fundar perceberam que era possível mobilizar financiamentos para o tratamento do arquivo. Além disso, o arquivo tinha uma centralidade institucional grande. Era visto como um patrimônio que legitimava a Fundação; e era visto como um repositório de projetos que a própria Fundação poderia levar adiante. É preciso lembrar que a Fundação havia sido criada pelo Darcy para dar continuidade às suas "utopias", como ele designava suas causas, mas, quando ele morreu, poucos anos depois, a instituição perdeu seu animador, a figura capaz de mobilizar pessoas e recursos em torno dos seus projetos.

\section{Seus "fazimentos"...}

Isso! Seus fazimentos, como ele também dizia. Mas é claro que a potência que motivava aquelas as utopias e fazimentos era o próprio Darcy. Com a sua morte, a Fundação se viu tendo que operar essa gramática dos fazimentos exatamente para dar consecução aos propósitos do Darcy, e o arquivo era um elemento importante nesse processo. Ter o arquivo e, mais do que isso,buscar naquela documentação projetos que Darcy deixou alinhavados, era estratégico no processo de legitimação da instituição. Isso para explicar porque havia uma expectativa grande com relação ao arquivo. Na época, a Fundação era administrada, fundamentalmente, por sua Vice-Presidente, Tatiana Memória, que tinha um nome sugestivo pra quem estava ali como guardiã da memória do Darcy. (risos). Ela havia colaborado com ele no período em que ele era vice-governador e assumiu a Secretaria de Cultura no primeiro Governo Brizola, se não me engano. Nesse momento, todo o programa de Educação, com a escola de tempo integral, os chamados Brizolões, foi estruturado. Tatiana tinha um enorme carinho pelo

Programa Especial de Educação e, por extensão, tinha grande preocupação com a 
documentação relativa a esse período de atuação do titular. Então, por exemplo, eu me lembro de uma ou duas vezes em que ela queria que eu incorporasse ao arquivo documentos que diziam respeito a esse programa educacional do Governo Brizola. Eu tentava convencê-la de que isso feria um dos princípios básicos da Arquivologia, que é o princípio de respeito aos fundos. Ou seja, aquele princípio de que o fundo tem que ser mantido íntegro, sem que haja a separação de documentos, mas também sem incorporações, pois o fundo deve refletir as atividades e as funções do titular, mas deve conter apenas o que foi por ele próprio acumulado. Então trazer um documento e integrá-lo ao fundo era uma coisa bastante herética.

\section{O fundo tem sua organicidade, né?}

Tem sua organicidade. Eu tentava convencê-la acerca desse princípio básico. E ela me dizia, com um documento $x$ nas mãos: "mas isso é uma besteira, porque, para entender direito essa documentação, esse relatório final aqui é fundamental". Mas o relatório não estava no arquivo do Darcy... Ela dizia: “Esses documentos só podem ser entendidos se esse relatório estiver aí também!". E eu falava: "Tatiana, veja bem, eu entendo seu ponto, mas vamos estabelecer uma coleção 'documentos avulsos' para colocar esse tipo de documento, não vamos integrar o documento ao fundo". Eu tentava explicar a ela o perigo de descaracterizar o fundo, de transformá-lo em uma grande coleção de e sobre Darcy Ribeiro e sua obra. Mas não era fácil, sobretudo, porque Tatiana era muito enérgica, e usava um argumento de autoridade que fazia muito sentido naquele espaço institucional: "Isso é besteira! Darcy não respeitava regras; era um sujeito anárquico...".

Até porque, quando ele assume os mandatos na vida pública, o número de registros aumenta exponencialmente, né?

Sim, é verdade. Mas isso já é outra dimensão, que tem a ver com o fato de o titular contar com um staff nos gabinetes que fica responsável pelo arquivamento. A gente estava falando primeiro dessa relação entre o depositário, ou a instituição 
depositária, e o próprio arquivo. No caso de instituições voltadas para a memória de um personagem, como no caso da Fundação Darcy Ribeiro, a conexão e a imbricação entre o arquivo e a instituição é muito grande. $\mathrm{O}$ arquivo legitima a instituição (isso acontece, aliás, em todas as instituições depositárias de arquivo), muitas vezes o arquivo justifica mesmo a existência da instituição. Em alguns casos, como no da Fundar, a instituição usa o arquivo nas suas atividades de rotina - para orientar suas políticas, suas estratégias de financiamento, enfim. Então é muito mais fácil ver esse tipo de conexão em instituições que são voltadas para o legado, ou a memória, de um personagem, né? Esse arquivo ganha centralidade, é como se ele precisasse ser exaustivo, como se ele precisasse ser completo do ponto de vista da vida do titular. Porque a própria instituição tem essa pretensão, de alguma maneira, de representar a trajetória do titular ou guardar os registros dessa trajetória. Então essa relação é muito mais tensa e muito mais complexa, talvez, do que numa instituição que não tenha essa marca. No caso da Fundação Darcy Ribeiro, eu percebi essa conexão e, vamos dizer, essa retro-alimentação entre arquivo e instituição. Outra coisa é isso que você me perguntou agora. De fato, no caso de arquivos de homens públicos - e aí não é uma especificidade do arquivo do Darcy -, as fases em que ocupam cargos públicos, via de regra, correspondem a saturações, do ponto de vista documental, no arquivo. Temos no CPDOC também uma série de arquivos de homens públicos que ocuparam cargos no Executivo e no Legislativo e a gente percebe que os períodos que correspondem aos mandatos desses titulares, muitas vezes, correspondem a fases muito bem documentadas. Claro que pode haver exceções. Mas, certamente, seja porque há maior preocupação por parte dos titulares, seja porque há um staff nos gabinetes que se ocupa da guarda dos documentos, observa-se em geral uma saturação. Isso também nos permite questionar, ou desnaturalizar um pouco, a imagem do arquivo pessoal como registro da intimidade, como registro da personalidade. Claro que há essa dimensão também, mas a minha sugestão é que os arquivos pessoais, de homens públicos, pelo menos, são empreendimentos a muitas mãos. 
Durante a organização do arquivo do Darcy, existiu algum momento em que a senhora teve que, ativamente, optar por uma forma de descrever os documentos? Ou seja, teve algum momento emblemático em que havia duas opções de "narrativa"?

Talvez, passados tantos anos dessa experiência, eu não saiba mais reconstituir um momento emblemático, se é que se pode falar nesses termos. Eu sei que foram muitas dúvidas sobre como ordenar aquele papelório muito extenso, acumulado segundo padrões distintos e que, de alguma maneira, colocava para a gente a dificuldade de operar apenas com o princípio funcional de organização, segundo o qual os arquivos devem ser organizados de acordo com a função ou atividade do titular, na qual a documentação foi produzida. No caso de um arquivo de homem público, por exemplo, as séries, ou os grandes conjuntos que compõem o arquivo devem corresponder às funções que ele exerceu. Às vezes isso não é tão simples. É algo que eu procuro discutir também na tese. Então, por exemplo, Darcy teve algumas temáticas que o acompanharam a vida toda, por exemplo, a relação dele com os índios, sua preocupação com as populações tradicionais. Isso aparece em vários momentos da vida dele, e não apenas no exercício de cargos específicos. Começa quando ele foi Chefe de Pesquisa do SPI, o Serviço de Proteção aos Índios, quando criou o Museu do Índio... Mas esse tema acompanhou a vida dele, então não era muito simples obedecer apenas ao princípio funcional. Claro que é sempre possível recuperar os temas com descritores - que possibilitam indexar a documentação a partir de palavras-chave. Mas, o fato é que, na hora de definir o quadro de arranjo, a gente se deparava com documentos sobre determinada temática, ou que faziam referência explícita a um assunto tratado quando ele ocupava determinada função, produzidos em outro contexto, que já não tinha a ver com o exercício dessa função. Nesse sentido, muitas vezes a documentação ultrapassava as fronteiras dos cargos e funções que ele ocupou. Me recordo, por exemplo, da série indigenismo- uma série temática, que contém subséries funcionais e temáticas. Então havia decisões complexas a tomar, não é? 
Era uma equipe de quantas pessoas?

Eu coordenava e tinha quatro estagiárias. Uma delas, numa segunda fase do projeto, se tornou auxiliar de pesquisa e mantivemos três estagiárias.

Ah, poucas pessoas!

Era muito pequena, e uma equipe que foi sendo formada no trabalho. Uma dessas estagiárias - Aline Camargo Torres - formada em Ciências Sociais, acabou enveredando para a área de arquivos e hoje trabalha no Arquivo Nacional. Muito legal essa dimensão de formação que os projetos podem ter.

Mas, de certa forma, uma equipe pequena ajuda a minimizar os conflitos...

Sem dúvida. Primeiro, eu tinha muita liberdade para definir, tomar as decisões estratégicas, definir o quadro de arranjo, por exemplo, mas também era um pouco solitário, porque eu tinha muitas dúvidas... Ter que tomar decisões que não seguiam o "bythe book", digamos, me deixou com conflitos internos algumas vezes (risos). E o fato de $o$ arquivo do Darcy ser muito grande amplificava essas coisas.

Eu imagino que não seguir o "bythe book" traga uma responsabilidade.

Sem dúvida. Você se pergunta se aquilo é conveniente ou não etc. Outro exemplo: há uma série grande também de correspondência organizada por correspondentes. Porque também percebi, no período do exílio dele, uma correspondência extensa e muito interessante com determinados personagens, tanto do campo acadêmico quanto do campo político, uma correspondência que em alguns casos se estendeu durante muitos anos. E me parecia que seria uma pena diluir essa correspondência em séries funcionais, inclusive porque elas não se relacionavam ao exercício de uma função, exatamente. Mas, é sempre uma escolha, porque todas as cartas do arquivo não estão nessa série por correspondentes. Então há momentos de definição, de escolha. Eu acho que, para isso, para resolver, vamos dizer, esse arbítrio, a 
única saída possível é declarar desde logo as decisões tomadas. Na abertura do instrumento de pesquisa, do inventário (seja ele um inventário analógico, seja, hoje em dia, uma base de dados disponível online), definir, explicar ao usuário quais foram as opções, e o que você pode encontrar ali. Deixar explícitas as decisões tomadas. Essas decisões, é claro, devem ser tomadas com base em princípios da Arquivologia, mas há sempre uma dimensão que extrapola, ao menos quando se trata de arquivos pessoais. Creio que explicitar a interferência do documentalista é uma forma de ajudar o pesquisador.

Em seu livro (O lugar do arquivo), você diz que "o exercício de seus muitos papeis traz a marca menos visível de um compromisso sempre renovado com as mesmas questões [...] Em lugar da multiplicidade, o arquivo nos propõe uma imagem que acentua a unidade e a repetição" (HEYMANN, 2012). Diante dessa reflexão, quais os principais elementos de unidade e repetição encontradas no legado de Darcy?

Essa discussão tem a ver, de um lado, com a relação entre o arquivo e a personalidade do titular, e de outro, com o potencial do arquivo para produzir "novas" interpretações. O Darcy produziu sua persona como um homem de múltiplos papéis, abusando da imagem de estar sempre se reinventando, ideia presente no título do excelente livro da Helena Bomeny Sociologia de um indisciplinado. Helena se apropria dessa ideia para analisar a atuação de Darcy no campo educacional. No entanto, é possível perceber que embora ele se afirmasse publicamente como esse homem irreverente, de múltiplas peles [...], na verdade, as mesmas causas o acompanharam ao longo de toda a sua vida. Para além da imagem do intelectual indisciplinado e irreverente, o que aparece na documentação é um personagem que persegue os mesmos temas. Isso se revela, por exemplo, no fato de ele se apropriar de determinado texto produzido em certo contexto e utilizá-lo em outro. Documentos que poderiam ser tomados como cópia ou versão um do outro, eram, na verdade, documentos de igual conteúdo, mas que remetiam a contextos diferentes. Porque Darcy usava o mesmo texto várias vezes; ele se repetia, embora construísse a imagem 
da revolução permanente. $\mathrm{O}$ arquivo servia como repositório onde ele buscava textos e referências que ele reutilizava [...] Mais do que temas ou causas que o acompanharam ao longo da vida, era possível perceber que ele resgatava projetos e textos. Ou seja, Darcy também era um homem de constâncias e obsessões. Ele produzia a autorepresentação do homem que estava sempre tendo novas ideias, mas essas ideias, muitas vezes, eram bastante antigas.

Considerando que os arquivos são construções sociais que revelam investimentos tanto do titular como da instituição custodiadora e dos agentes responsáveis pelo seu tratamento, como você vê a transferência do arquivo para Universidade de Brasília $($ UnB)?

Primeiramente, faço uma pequena ressalva. De fato, eu acho que os arquivos revelam investimentos dos titulares, mesmo em suas lacunas ou silêncios. Às vezes, dos doares ou herdeiros, que projetam no acervo expectativas que o próprio titular muitas vezes não tinha, ao menos da mesma forma. Para as instituições, sejam elas dedicadas à história de um personagem sejam instituições mais plurais, como é o caso do CPDOC, mas também na Casa de Rui Barbosa e de tantas outras, os arquivos conferem prestígio. No caso dos responsáveis pela organização do arquivo, a questão se coloca de uma forma um tanto diferente, embora eu considere que exista uma dimensão subjetiva nas decisões relativas à organização e descrição da documentação. Entendo que as representações acerca do titular, as interpretações acerca de sua atuação e o "lugar" institucional do arquivo podem exercer influência nas definições e decisões dos documentalistas, mas talvez esse tema deva ser tratado com mais vagar, em outra ocasião... Então, voltando à sua pergunta, acho importante matizar um pouco a frase, se não parece que todos esses agentes têm as mesmas expectativas em relação aos arquivos. Dito isto, qual seria o impacto da transferência do arquivo para a UnB? Sei que o arquivo está fechado à consulta lá, segundo a última informação que eu tive. Mas, sei que houve uma grande expectativa em relação à transferência do arquivo para Brasília. Ocorreu em 2009, quando o Presidente da Fundar, Paulo Ribeiro, sobrinho de Darcy, tinha assumido as rédeas da instituição, após o falecimento de Tatiana Memória. 
Essa história com a UnB, porém, é antiga. Darcy tentou negociar um terreno na UnB, com o reitor, para criar lá a Fundação. Ele dizia que queria instalar no campus da universidade o Beijódromo, um espaço para namorar, tudo com aquela sua marca irreverente. Na época, Darcy não conseguiu, pois o reitor não the cedeu um terreno, que era o que ele queria. Em2009, do ponto de vista da Fundar, a transferência tinha o sentido de conectar a Fundação - por meio do arquivo - ao ambiente acadêmico. Eu entrevistei o Paulo Ribeiro algum tempo antes, quando estava redigindo a tese. Ele buscava essa conexão com o campo acadêmico e creio que viu a criação do Memorial Darcy Ribeiro, na UnB, a chance para essa aproximação. Do ponto de vista da UnB, me parece, o arquivo trazia o "mana" de Darcy para a UnB, sua ousadia, seu idealismo. Isso depois de a Universidade ter passado por uma crise séria, na qual o reitor de então foi acusado de corrupção etc. A transferência do arquivo foi associada à necessidade de recuperar o ideal e a missão da Universidade. Houve grandes expectativas em torno dessa transferência.

Você gostaria de deixar algum conselho para os pesquisadores em arquivos?

Talvez uma provocação: desconfiem dos arquivos e das formas de acessá-los, sobretudo, em ambientes informatizados. Não se trata de uma visão hiper relativista, segundo a qual tudo é construção, não é isso. Mas olhem com interesse para além daquela primeira resposta, inquiram os instrumentos de consulta, bases de dados, o que elas revelam em primeira mão para a pesquisa, o que não é visível, o que se esconde. No caso dos arquivos, se for possível, se perguntem um pouco sobre esses processos de construção. Não assumam a fonte como um dado a ser utilizado apenas para responder outra pergunta. Perguntem sobre essa fonte. É válido e faz parte dos procedimentos do historiador. Mas sugiro ir um pouco além daquilo que se chama de crítica interna e externa aos documentos. Talvez uma crítica do arquivo. E, por outro lado, faço um convite. Os arquivos são objetos muito interessantes de pesquisa, como espero ter deixado claro no livro e em outros textos. Vivemos um momento de inflação de memórias e arquivos, o que significa um campo crescente de pesquisa. Visitem 
nesse campo e tragam suas reflexões. Os arquivos estão em toda parte, e são apaixonantes!

\section{Referências}

LATTES. Luciana QuilletHeymann. Plataforma Latteswebsite. 2016. Disponível em: $<$ http://buscatextual.cnpq.br/buscatextual/visualizacv.do?id=K4787472J2>. Acesso em: 03 jul. 2016.

CPDOC. Luciana QuilletHeymann. CPDOC/FGV website. 2015. Disponível em: <http://cpdoc.fgv.br/equipe/LucianaHeymann>. Acesso em: 02 jul. 2016.

HEYMANN, Luciana Quillet. O lugar do arquivo: a construção do legado de Darcy Ribeiro. Rio de Janeiro: Contra capa, FAPERJ, 2012. 